\title{
Sensitivity of a mesoscale model to different convective parameterization schemes in a heavy rain event
}

\author{
I. Gómez ${ }^{1}$, F. Pastor ${ }^{1}$, and M. J. Estrela ${ }^{2}$ \\ ${ }^{1}$ Laboratorio de Meteorología-Climatología, Unidad Mixta CEAM-UVEG, Instituto Universitario Centro de Estudios \\ Ambientales del Mediterráneo CEAM - UMH, Programa de Meteorología-Climatología, Paterna (Valencia), Spain \\ ${ }^{2}$ Laboratorio de Meteorología-Climatología, Unidad Mixta CEAM-UVEG, Departament de Geografía Física, Universitat de \\ València, Valencia, Spain
}

Received: 12 May 2010 - Revised: 4 November 2010 - Accepted: 24 December 2010 - Published: 7 February 2011

\begin{abstract}
The Valencia region, on the Mediterranean coast of the Iberian Peninsula, is propitious to heavy precipitation, especially the area encompassing the South of Valencia province and the North of the Alicante province. In October 2007 a torrential rain affected the aforementioned area, producing accumulated rainfall values greater than $400 \mathrm{~mm}$ in less than $24 \mathrm{~h}$ and flash-floods that caused extensive economic losses and human casualties. This rain event has been studied in numerical experiments using the Regional Atmospheric Modeling System. The present paper deals with the effect of using the different convective parameterizations (CP) currently implemented in the Regional Atmospheric Modeling System (Kuo and Kain-Fritsch) in the forecast results, in particular on precipitation forecast. Sensitivity tests have been run with and without these parameterizations activated in a series of combinations of the different grids. Results are very different depending on the model convective parameterization setting. A statistical verification has also been undertaken by calculating different skill scores for each simulation in the experiment.
\end{abstract}

\section{Introduction}

Torrential rains and flash-floods are common in the Western Mediterranean, especially from late summer to autumn. Such heavy rain events can cause high economic losses and, sometimes, human casualties. Thus, their study and proper

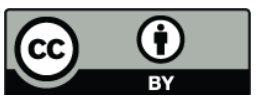

Correspondence to: I. Gómez (igor@ceam.es) forecasting is an important issue in Mediterranean meteorology. Numerous efforts addressing this problem from different points of view have been made during recent years. Some authors have studied the climatology of cyclogenesis or heavy rain events in the Mediterranean (Maheras et al., 2001; Trigo et al., 2002), their synoptic settings and genetic mechanisms (Doswell III et al., 1998; Jansa et al., 2001; Estrela et al., 2003), and their dynamics and structure (Lagouvardos et al., 1996). Studies have also focused on the evolution and trends in heavy rainfall events in the Mediterranean, finding an increasing trend in both the number of events and the amount of rain precipitated (Alpert et al., 2002; Peñarrocha et al., 2002; Millán et al., 2005). The Fourth Assessment Report of the Intergovernmental Panel on Climate Change (Solomon et al., 2007) states that, in future climate scenarios in the Mediterranean region, heavy-rain events are expected to be more intense.

Likewise, there are numerous modelling studies of torrential rain events and deep cyclones in the Mediterranean. These studies comprise the simulation of idealized conditions for rain events (Bresson et al., 2009), the implementation or performance of analysis or forecast systems (Lagouvardos et al., 1999; Davolio et al., 2009), model sensitivity tests (Davolio et al., 2009), case studies (Federico et al., 2008), the influence of different parameters on model results, such as orography (Federico et al., 2008; Miglietta and Regano, 2008; Pastor et al., 2010), sea surface temperature (Pastor et al., 2001; Homar et al., 2002; Lebeaupin et al., 2006), latent heat fluxes (Romero et al., 2000; Homar et al., 2002; Federico et al., 2008) or other factors (Meneguzzo et al., 2004).

Published by Copernicus Publications on behalf of the European Geosciences Union. 


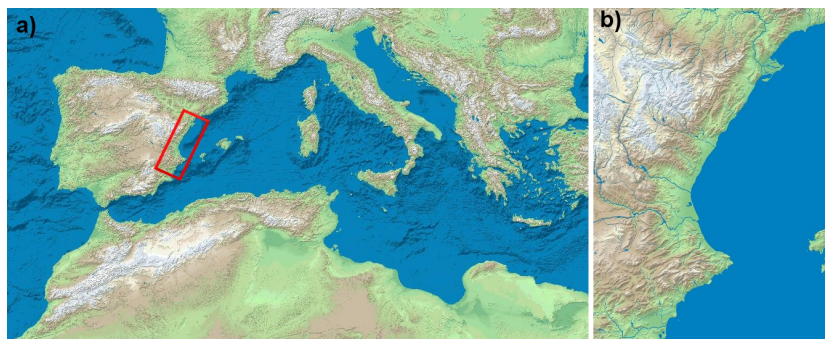

Fig. 1. Location (a) and orography (b) of Valencia region in the Mediterranean area

Within the Iberian Peninsula, the Valencia region (Fig. 1) is periodically affected by heavy rain events. There are numerous studies on the torrential rain events in this area, ranging from their spatial distribution and synoptic situations (Peñarrocha et al., 2002) to the influence of different factors such as sea surface temperature in the numerical modelling of torrential rain (Pastor et al., 2001). In October 2007 a torrential rain event took place in the Valencia region, affecting mainly the coastal areas and nearby mountains in the centersouth of the region. More than $400 \mathrm{~mm}$ in $24 \mathrm{~h}$ were recorded at some stations in these areas, with less intense rainfall in the rest of the region. A detailed description of this rain event, the meteorological situation that led to the torrential rains, the data recorded and the results of numerical modelling using Regional Atmospheric Modelling System (RAMS) are given in Pastor et al. (2010).

The activation or not of the CPs is still an open question in numerical modelling. In their work, Warner and Hsu (2000) studied the effects of the activation of CPs on the precipitation forecast in the simulation of a summer season convection. The authors find great differences in the model results in high resolution, where the convection is explicitly resolved, depending on the use of $\mathrm{CP}$ in the coarser grids. They also find different physical effects in the inner grid for the different simulations that can be summarized in a warming and drying above $500-700 \mathrm{hPa}$ and a cooling and moistening below.

Convective parametrization schemes currently available in RAMS assume the grid size in the horizontal to be around $20 \mathrm{~km}$ or more and that below $2 \mathrm{~km}$ horizontal resolution, no convective parametrization should be activated. As those convective adjustment schemes were developed for around $20 \mathrm{~km}$ resolution grids, their use at intermediate and high grid resolution has to be carefully considered and evaluated. In high resolution model grids, it is not necessary to activate any CP scheme as it is possible to explicitly resolve convection. However, Kotroni and Lagouvardos (2004) show that a KF scheme should be activated at $2 \mathrm{~km}$ grid resolution in the case of convective storms. The same authors also studied the skill of MM5 model with different combinations of convective parameterization and microphysical schemes

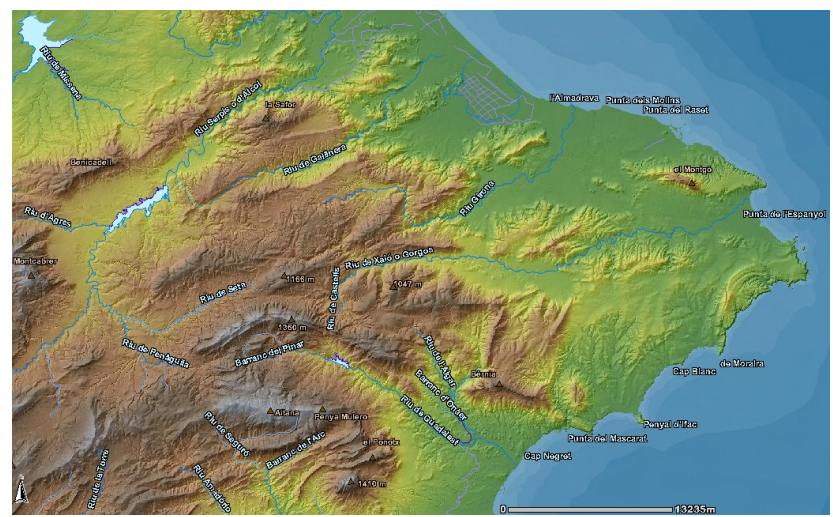

Fig. 2. Northern Alicante province orography. Courtesy of Conselleria de Medi Ambient, Aigua, Urbanisme i Habitatge de la Generalitat Valenciana

(Kotroni and Lagouvardos, 2001), obtaining good forecasting skill using the KF scheme. Mazarakis et al. (2009) also showed that KF scheme produced good forecasting skills in cases of intense convective activity.

The present study tries to establish the feasibility of activating the RAMS available CP schemes for intermediate and high resolution horizontal scales. This is done by investigating the effects of the two CP schemes implemented in RAMS model. For this purpose, a series of high resolution simulations of the October 2007 rain event have been carried out using different combinations of the two convective schemes in the model grids. We have used the KainFritsch (KF hereafter) (Kain and Fritsch, 1993) and the Kuo convective parametrization schemes (Molinari, 1985), which are implemented in the RAMS model. The KF scheme was added to the model (Castro et al., 2002) as an alternative to the Kuo scheme, which had previously been the only deep cumulus convection scheme available in the model.

\section{Rain event description}

On 11-12 October 2007 a heavy rain event took place in the Valencia region with a maximum accumulated precipitation recorded value of $437.6 \mathrm{~mm}$ and values above $300 \mathrm{~mm}$ at other stations during the whole event ( $48 \mathrm{~h})$. A short description of the rain event is given in this section; more detailed information can be found in Pastor et al. (2010).

The rain event spread across the Valencia region with the most intense precipitation, both in accumulated value and rain intensity, recorded on the northeast coast of Alicante province and surrounding areas. The orography of this area (Fig. 2) is constituted by a narrow coastal area and a number of mountain ranges aligned Southwest to Northeast, varying in height from 300 to $700 \mathrm{~m}$ with some of the more inland peaks higher than $1000 \mathrm{~m}$. These mountain ranges separate 

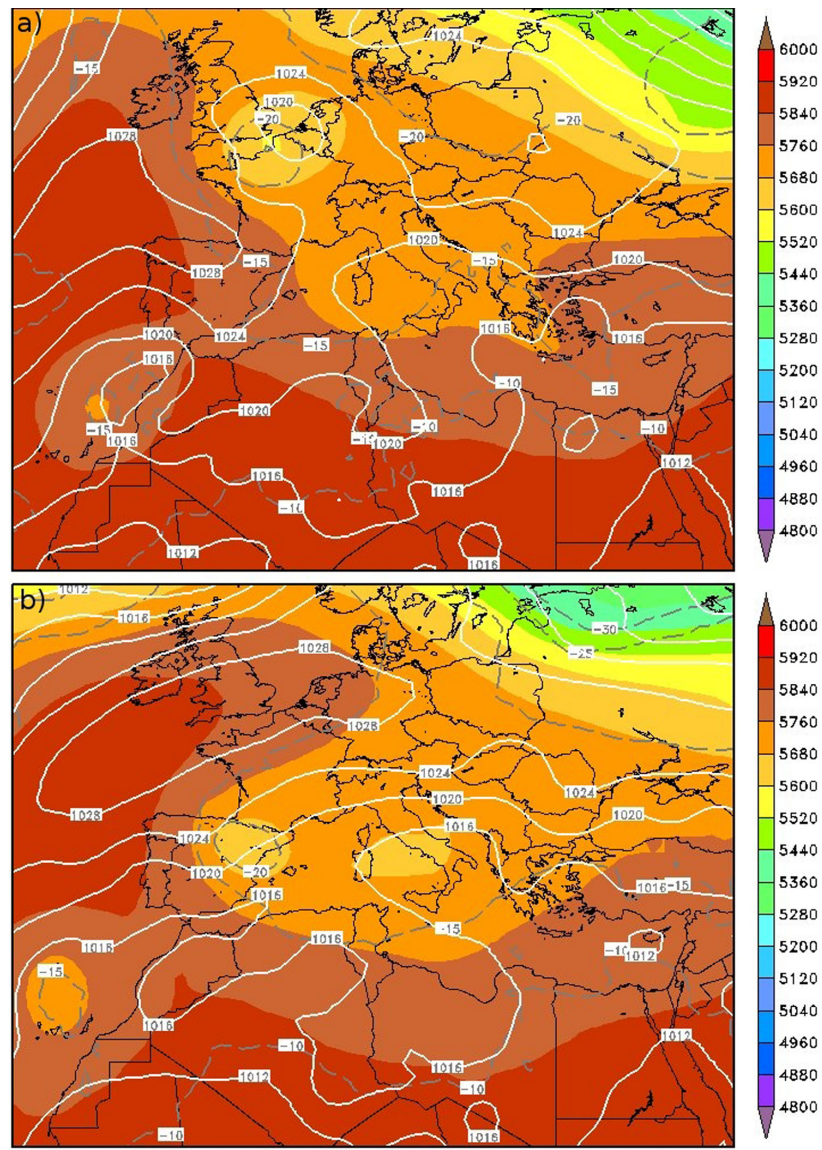

A600

5920 5840 5760 5680 5600 5520 5440 5360 5280 5200 5120 5040 4960 …

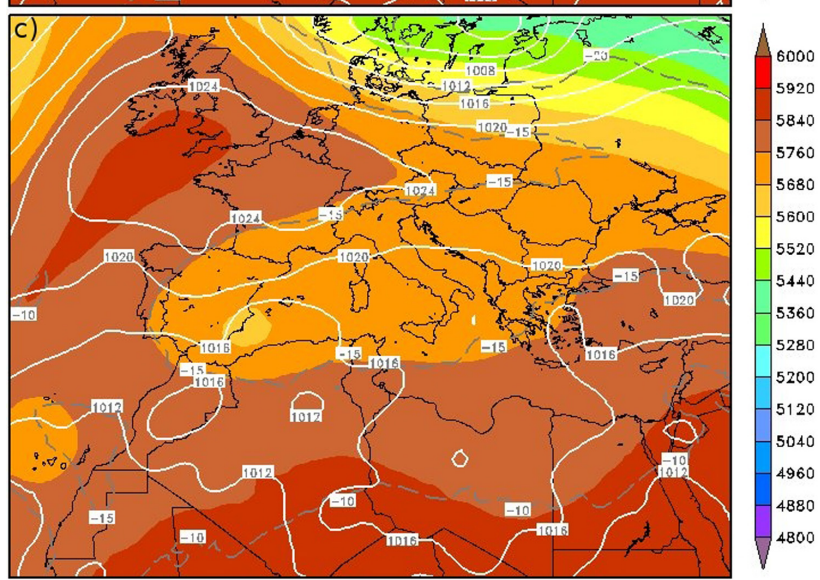

Fig. 3. Sea level pressure (hPa, solid line), geopotential height (gpm, shaded color) and temperature in ${ }^{\circ} \mathrm{C}$ (dashed line) at $500 \mathrm{hPa}$ on (a) 10 October 2007 at 00:00 UTC, (b) 11 October 2007 at 00:00 UTC and (c) 12 October 2007 at 00:00 UTC, obtained from NCEP Reanalysis

a series of long, narrow valleys, open to the coast and well exposed to maritime northeast and east winds.

The synoptic situation (Figs. 3 and 4) was mainly an easterly advection across the Mediterranean, driven along its southern side by a strong anticyclone that remained station-

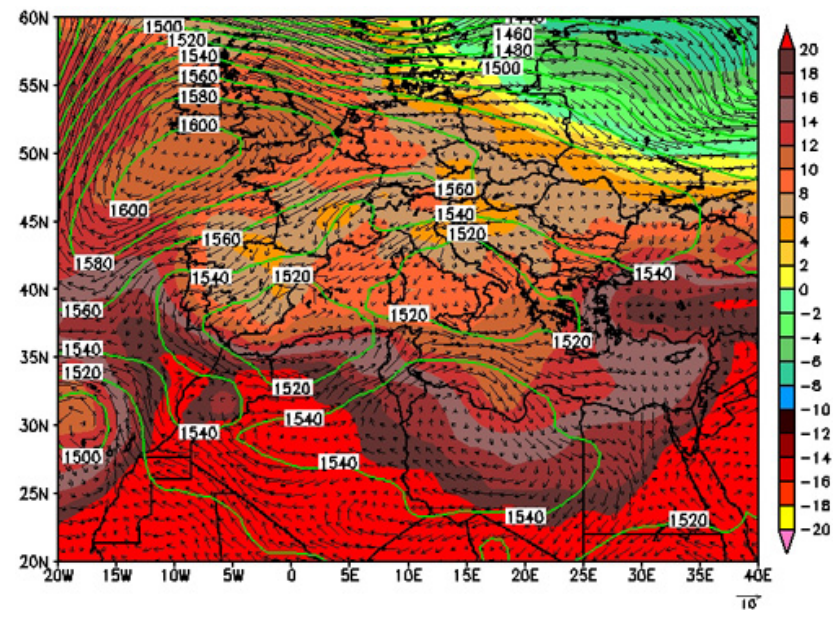

Fig. 4. Temperature $\left({ }^{\circ} \mathrm{C}\right.$, shaded), wind (arrows) and geopotential height (gpm, contoured) at $850 \mathrm{hPa}$ on 11 October 2007 at 12:00 UTC obtained from NCEP Reanalysis

ary over Western and Northern Europe. This easterly flow was reinforced in its final stretch and driven to the Valencia region by low pressures present over Northern Africa. At mid- levels, a cold(er) advection from the Northeast can be seen during most of the event (Fig. 4), although close to the moment of maximum precipitation, and for a short period, a wind convergence area can be seen at $850 \mathrm{hPa}$ level over the sea to the East at 06:00 UTC on 12 October with northeasterly winds coming from the northern half of the Mediterranean and southeasterly (warmer) winds coming from Northern African coast. Noteworthy is the presence of an isolated upper-level low over the Valencia region by 11 October. This situation was derived from the arrival of a moist and potentially unstable air mass from the Mediterranean sea to the Valencia coast. The coincidence of these factors favored, beside the orographic trigger, an appropriate environment for the initiation of the rain event.

The rain event affected the whole Valencia region, but the highest values were markedly focalized in an area to the south of the Gulf of Valencia, in the northeast Alicante province and the southeast Valencia province (Fig. 6). In most of this area precipitation values exceeding $200 \mathrm{~mm}$ in $24 \mathrm{~h}$ accumulated while some stations recorded values above $400 \mathrm{~mm}$. From Fig. 6 it can be seen that most of the rainfall occurred on 12 October as the rain event started during the last hours of 11 October and lasted for about $16 \mathrm{~h}$ until the first half of 12 October. Table 1 shows the highest accumulated precipitation recorded in 90 stations by the meteorological networks of Fundación CEAM, Spanish Meteorological Agency (AEMET), hydraulic authorities of the Confederación Hidrográfica del Júcar (CHJ) and the Spanish Ministry of Agriculture (stations selected in Table 1 are shown in Fig. 5). 


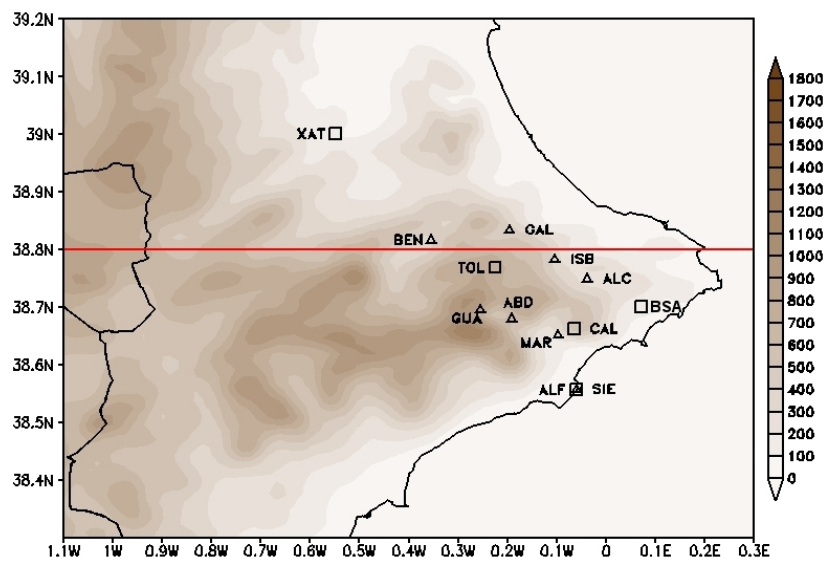

Fig. 5. Location of the meteorological stations in Table 1 and location of vertical cross sections on RAMS Grid 4.

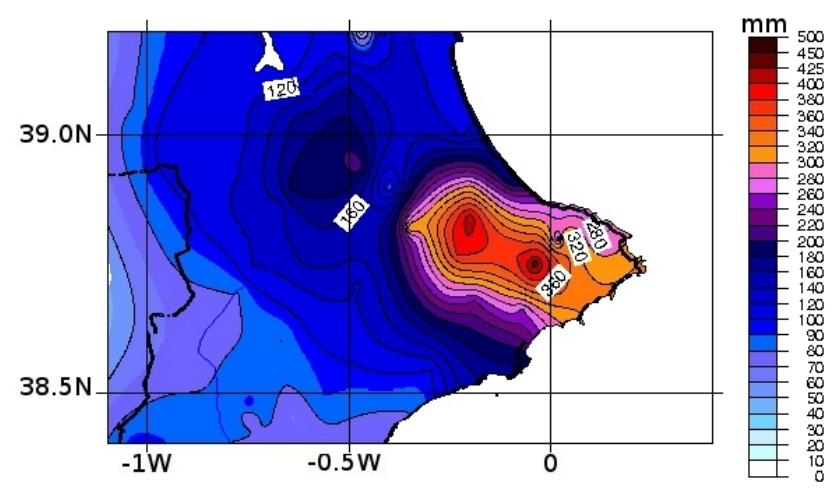

Fig. 6. 48-h accumulated precipitation (11-12 October 2007). Data recorded by CEAM Meteorology Department, AEMET and Confederación Hidrográfica del Júcar

\section{RAMS model and verification}

In this work we have used the 6.0 non-hydrostatic version of the RAMS model; detailed information about the model is available in the papers by Pielke et al. (1992) and Cotton et al. (2003). In previous works at Fundación CEAM studies with RAMS, model optimum configuration for mesometeorological studies in the Valencia region has been investigated by Salvador et al. (1999). RAMS has also been used for the evaluation of the effects of sea surface temperature on torrential rains (Pastor et al., 2001) and the study of air pollution dispersion (Pérez-Landa et al., 2007). RAMS has likewise been used in the study of torrential rains in the Mediterranean area by other authors like Lagouvardos et al. $(1996,1999)$ Meneguzzo et al. (2004), Federico et al. (2008), Pastor et al. (2010) and Gómez et al. (2010).
Table 1. Accumulated precipitation ( $\mathrm{mm}$ ) during 11-12 October 2007.

\begin{tabular}{lcccc}
\hline \multirow{2}{*}{ Station } & \multicolumn{4}{c}{ Accumulated precipitation (mm) } \\
& Acronym & $11 / 10 / 07$ & $12 / 10 / 07$ & Total \\
\hline Alcalalí & ALC & 22.0 & 415.6 & 437.6 \\
Gallinera & GAL & 15.2 & 398.0 & 413.2 \\
Tollos & TOL & 25.6 & 359.8 & 385.4 \\
Isbert & ISB & 14.4 & 365.2 & 379.6 \\
Benissa & BSA & 181.0 & 154.0 & 335.0 \\
Beniarrés & BEN & 18.8 & 296.4 & 315.2 \\
Abdet & ABD & 12.0 & 262.6 & 274.6 \\
Marina Baixa & MAR & 11.0 & 245.8 & 256.8 \\
Callosa d'En Sarriá & CAL & 18.0 & 236.6 & 254.6 \\
Guadalest & GUA & 8.0 & 230.4 & 238.4 \\
Xátiva & XAT & 16.8 & 169.2 & 186.0 \\
Sierra Helada & SIE & 9.0 & 170.4 & 179.4 \\
Alfás del Pi & ALF & 15.3 & 154.8 & 170.1 \\
\hline
\end{tabular}

\subsection{Initial conditions and model configuration}

The initial and boundary atmospheric conditions used for the simulations in this paper were provided by the National Centre for Environmental Prediction (NCEP) global Final Analyses (FNL) and are available every $6 \mathrm{~h}$ at $1 \times 1$ degree resolution. Four-Dimensional Data Assimilation (FDDA) techniques are used to define the forcing at the lateral boundaries of the outermost five grid cells of the largest simulation domain. For the surface boundary conditions we have used land cover datasets from the US Geological Survey.

The LEAF-3 soil-vegetation surface scheme is applied to evaluate sensible and latent heat flux exchanges with the atmosphere, using prognostic equations for temperature and soil moisture. LEAF-3 has been prescribed with a homogeneous soil texture of the clay-loam type. The soil column is subdivided into 11 layers down to a depth of $2 \mathrm{~m}$ and its moisture initialized with a uniform profile at a value of $0.38 \mathrm{~m}^{3}$ of water per cubic meter of total volume. The initial soil temperature profile is obtained by subtracting $2.3^{\circ} \mathrm{C}$ from the surface air temperature in the top soil layer. Temperature linearly decreases down to a decrease of $1{ }^{\circ} \mathrm{C}$ in the bottom soil (Pérez-Landa et al., 2007). The climatological sea surface temperature provided by RAMS is prescribed over the sea.

Four domains of decreasing size at increasing spatial resolution have been used in the RAMS simulations in this paper. Four, two-way interactive, nested domains were configured at grid spacings of $40.5,13.5,4.5$ and $1.5 \mathrm{~km}$, respectively (Fig. 7). Regarding vertical discretization, a 45 level stretched vertical coordinate has been used with a $30 \mathrm{~m}$ spacing near the surface that gradually increases to $1000 \mathrm{~m}$ near the model top, which is located at about $17000 \mathrm{~m}$, and with 15 levels in the lower $1000 \mathrm{~m}$ (model grid parameters are summarized in Table 2). The Chen and Cotton (1983) radiation scheme, accounting for clouds to calculate short 
Table 2. Rams model settings

\begin{tabular}{cccccc}
\hline Grid & $\mathrm{nx}$ & $\mathrm{ny}$ & $\mathrm{nz}$ & $\mathrm{dx}(\mathrm{m})$ & $\mathrm{t}(\mathrm{s})$ \\
\hline 1 & 90 & 80 & 45 & 40500 & 60 \\
2 & 110 & 101 & 45 & 13500 & 30 \\
3 & 83 & 101 & 45 & 4500 & 15 \\
4 & 128 & 101 & 45 & 1500 & 5 \\
\hline
\end{tabular}

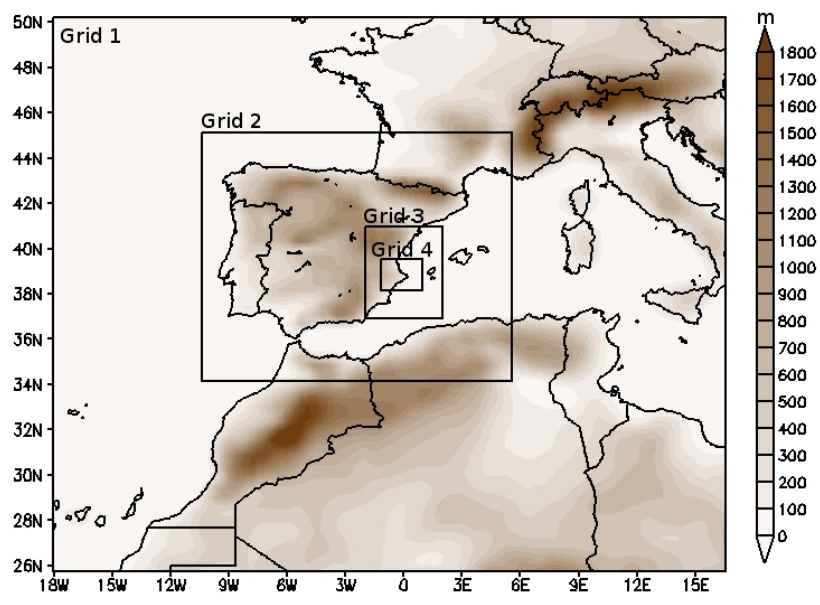

Fig. 7. RAMS model domains and orography (m)

and long-wave radiation, is used in RAMS model. The cumulus parameterization schemes implemented in model version 6.0 are the Kuo and the Kain-Fritsch. In our simulations, they are activated or not in a set of combinations of the model grids. The cloud and precipitation microphysics scheme from Walko et al. (1995) has been applied in all the domains. The rain event took place from the last hours of 11 October to the first half of 12 October; thus, we have run our simulations during $48 \mathrm{~h}$, starting at 00:00 UTC on the 11th of October 2007 and finishing at 00:00 UTC on 13 October.

To determine whether activating the Kuo and KF schemes in different grid resolutions affects/improves precipitation forecasting, a series of numerical simulations have been performed. Cumulus parameterization schemes have been activated/deactivated in the model grids for a set of numerical experiments, yielding a total of eight different simulations (Table 3). Although model Grid 4 has enough high spatial resolution to explicitly resolve convection and no parameterization is needed, we have run a experiment with the Kuo scheme activated in inner Grid 4; the experiment with the KF scheme active in Grid 4 did not succesfully finish. An additional experiment has been run without any $\mathrm{CP}$ active in any of the model grids (NoC).
Table 3. RAMS convective parameterization settings

\begin{tabular}{lllll}
\hline Exps. & Grid 1 & Grid 2 & Grid 3 & Grid 4 \\
\hline Kuo1 & Kuo & - & - & - \\
Kuo2 & Kuo & Kuo & - & - \\
Kuo3 & Kuo & Kuo & Kuo & - \\
Kuo4 & Kuo & Kuo & Kuo & Kuo \\
KF1 & Kain-Fritsch & - & - & - \\
KF2 & Kain-Fritsch & Kain-Fritsch & - & - \\
KF3 & Kain-Fritsch & Kain-Fritsch & Kain-Fritsch & - \\
NoC & - & - & - & - \\
\hline
\end{tabular}

\subsection{Verification methodology}

To evaluate RAMS precipitation forecasting skill, a quantitative assessment has been undertaken for the study area (model Grid 4). The methodology is based on a statistical verification by means of several widely-used non-parametric skill scores (Mariani et al., 2005; Mazarakis et al., 2009). For the statistical evaluation, hourly accumulated precipitation data from 50 rain gauges, 14 operated by CEAM and 36 by $\mathrm{CHJ}$, have been used.

For the observed and forecasted values, a $2 \times 2$ contingency table has been built to categorize the possible combinations of forecasting and observed events above or below a given threshold. The threshold set is based on the seven different thresholds already used in the study by Mariani et al. (2005). Due to the high intensity of the observed space/time rainfall peak, high values up to $80 \mathrm{~mm} / 12 \mathrm{~h}$ are included. In this table, the four different categories are defined in terms of whether or not the observation and the forecast exceed the threshold at the same time. The sample size is the sum of these four categories and corresponds to the total number of forecast-observation pairs over the verification period.

As only one event is considered, we have used the methodology proposed by Hamill (1999) and subsequently applied by Mariani et al. (2005). In this approach, the skill scores are calculated as a sum of contingency tables instead of as an average of contingency tables. This makes the skill scores less sensitive to small changes in the contingency table population. Thus, the hourly precipitation records are tallied up on several contingency tables on the basis of accumulation time. Then, Areal Bias (AB), Probability of Detection (POD), False Alarm Rate (FAR), Critical Success Index (CSI) and Heidke Skill Score (HSS) are calculated.

\section{Results and discussion}

In this section we will check the RAMS model forecast on model Grid 4 against recorded data to determine which model configuration better fits the observations mentioned in Sect. 2 (Fig. 6). Daily accumulated precipitation data have 
been used to check simulated accumulated precipitation and spatial distribution while hourly values have been compared with the temporal evolution of model forecasts. Statistical verification is based on hourly accumulated precipitation data that permitted a 12-h compute of accumulated precipitation following the procedure by Mariani et al. (2005) described above. In both cases, precipitation observations are compared with model Grid 4 results at the closest points to each station.

\subsection{Accumulated precipitation and spatial location}

RAMS model total accumulated precipitation for the whole simulation is also shown in Fig. 8 (00:00 UTC on 11 October to 24:00 UTC on 12 October). On 11 October, the Kuo1 experiment shows a very good performance in both the location of the maximum precipitation area and the predicted accumulated precipitation with respect to the observed data, but it fails to find some local precipitation peaks inland. In contrast, the Kuo2 experiment almost completely misses the maximum rain area but captures a local maximum on the coast to the north of the absolute maximum area. Kuo3 shows a better performance than Kuo2 in locating the maximum rain area but it locates it slightly to the north of its actual position and gives peak values greater than the observed ones. Moreover, another high intensity precipitation area appears to the north of the Grid 4 domain, thus strongly overpredicting the precipitation. In the case of Kuo4 the precipitation maxima forecasted is displaced to the east over the sea and rainfall values are underestimated over land.

When using the Kain-Fritsch parameterization scheme, results from the KF1 experiment show the maximum precipitation area displaced to the south and over the sea, and also underpredict the values. In the KF2 experiment, accumulated precipitation values are still low, and only a small area with values over $90 \mathrm{~mm}$ is correctly located. KF3 yields the worst results of all the experiments, showing very low or even no precipitation in some parts of the domain. Some areas with moderate precipitation not present in the recorded values also appear inland. Globally, the Kuo experiments provide more realistic results than the Kain-Fritsch for both the spatial distribution of precipitation and the quantitative precipitation forecasts. It should be noted that in all the experiments except KF3, an area with moderate to heavy precipitation appears offshore. In the Kuo3 experiment, this rain area is closer to the coast, thus generating the unrealistic maximum area mentioned above. Results from the NoC experiment show a narrow precipitation band on the coast, almost missing precipitation inland, with values lower than the recorded ones.

Most of the heavy rain in the event fell before 12:00 UTC on 12 October (Pastor et al., 2010). This can be seen in the results (not shown) from the four Kuo, KF1 and NoC experiments, while KF2 and KF3 give poor results with very low precipitation values. In the Kuol experiment, the max- imum rain area is not correctly reproduced as it misses the southern part of the maximum precipitation area and extends more inland to the Northwest than was observed. Regarding total values, this experiment again underpredicts precipitation with peak values above $120 \mathrm{~mm} /$ day. The Kuo2 experiment shows similar spatial patterns to those seen in Kuo1 but with higher precipitation values $(240 \mathrm{~mm} /$ day $)$, although still underpredicted, and extending more to the south than Kuo1 but still with very low values. The best results of the Kuo scheme experiments are obtained in the Kuo3 and Kuo4 experiments. The spatial distribution of accumulated precipitation in Kuo3 correctly fits the recorded precipitation in both extension and location. Nevertheless, even though Kuo 3 yields greater values than Kuo2, above $240 \mathrm{~mm}$, and a broad area over $100 \mathrm{~mm}$, it still undepredicts the precipitation values. Kuo4 shows the highest precipitation peak of above $300 \mathrm{~mm}$ very close to the maximum recorded values but in a smaller area than the actual one and missing the peak precipitation areas present to the south over the coast. In all Kuo experiments the rain area extends southwest to northeast and goes over the sea.

From the experiments using the Kain-Fritsch convective parameterization scheme, only KF1 gives relatively good results on 12 October while the KF2 and KF3 experiments show very low, unrealistic accumulated precipitation values. In the KF1 experiment the high precipitation area is less extensive than the real one but it is well-located. The maximum values are also underestimated, as in all Kuo scheme experiments, with a maximum point value of $200 \mathrm{~mm}$. The other two Kain-Fritsch experiments, KF2 and KF3, show very low values below 80 and $50 \mathrm{~mm}$ respectively, and the location of the maxima is displaced to the North and inland. The NoC simulation correctly reproduces the precipitation area but underpredicts values with a maximum above $160 \mathrm{~mm}$.

\subsection{Temporal evolution of precipitation}

After studying the accumulated precipitation and its spatial distribution, the time evolution of the RAMS precipitation forecast has been analysed. From the data available within the study area, we have selected stations with hourly data and plotted observed precipitation against RAMS forecasted values; three selected precipitation plots are shown in Fig. 9, these stations are the ones with the highest accumulated precipitation and hourly data available.

During the first $18 \mathrm{~h}$ of the simulation, very little or no precipitation was recorded. At most stations, the Kain-Fritsch, Kuo1, Kuo2 and Kuo4 experiments produced almost no precipitation while the Kuo3 experiment shows some precipitation peaks although no actual precipitation was recorded. The heavy rainfall event started at most stations between 20 and $24 \mathrm{~h}$ after the start of the simulation. All the Kuo scheme experiments show the onset of the precipitation event correctly around 18 simulation hours, although Kuol gives precipitation intensities that are too high, as can be seen for the 

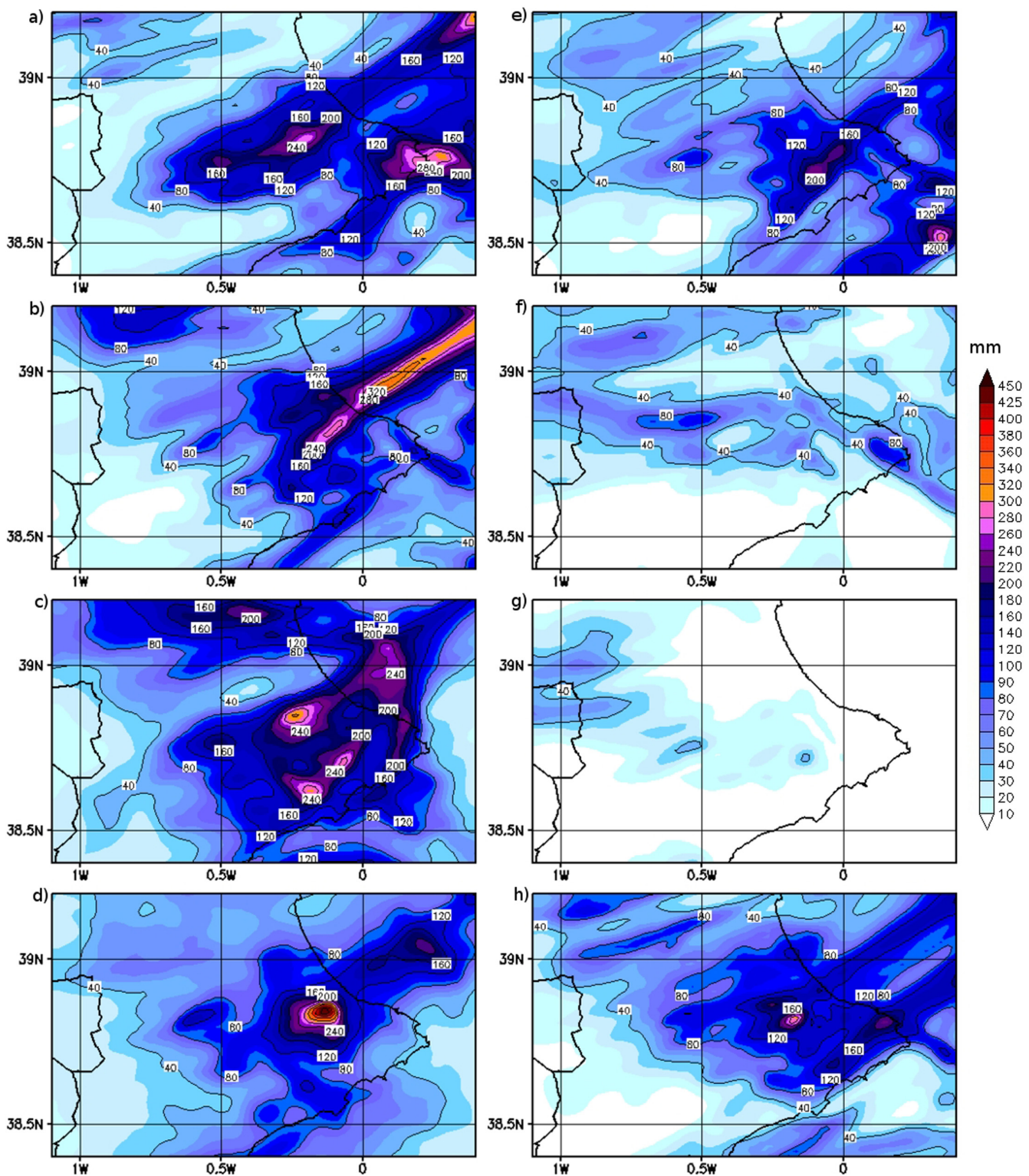

Fig. 8. RAMS Grid 4 48-h accumulated precipitation forecast in mm for the whole event: (a) Kuo1, (b) Kuo2, (c) Kuo 3, (d) Kuo4, (e) KF1, (f) $\mathrm{KF} 2$, (g) KF3 and (h) NoC.

three stations in Fig. 9. Kuo4 completely misses maximum precipitation time in the three stations, giving its maximum intensity with several hours of delay.

Throughout the rain period, the KF2 and KF3 experiments yield very poor results as they produce almost no precipitation, except at the few stations where KF2 shows some precipitation peaks with very low values. In contrast, KF1 yields the best results of all the KF experiments. Its results are similar to the Kuo scheme, but they are even better at reproducing the precipitation maximum intensity at some stations, such as Alcalalí station (Fig. 9a). The NoC experiment shows good skill in determining the onset of the event but it also under- predicts intensity values. The maximum precipitation time for NoC experiment shows a delay regarding observed values, especially in the case of Alcalalí station. In general, the Kuo scheme experiments reproduce the evolution of the precipitation event well, although the precipitation values they give are always too low, about $50 \%$ or more with respect to real precipitation intensities. At most stations, the best results on event duration and peaks are produced by the Kuo2 and Kuo3 experiments, while in Kuo1 the precipitation starts too soon and does not reproduce the precipitation intensities during rainfall well enough. 

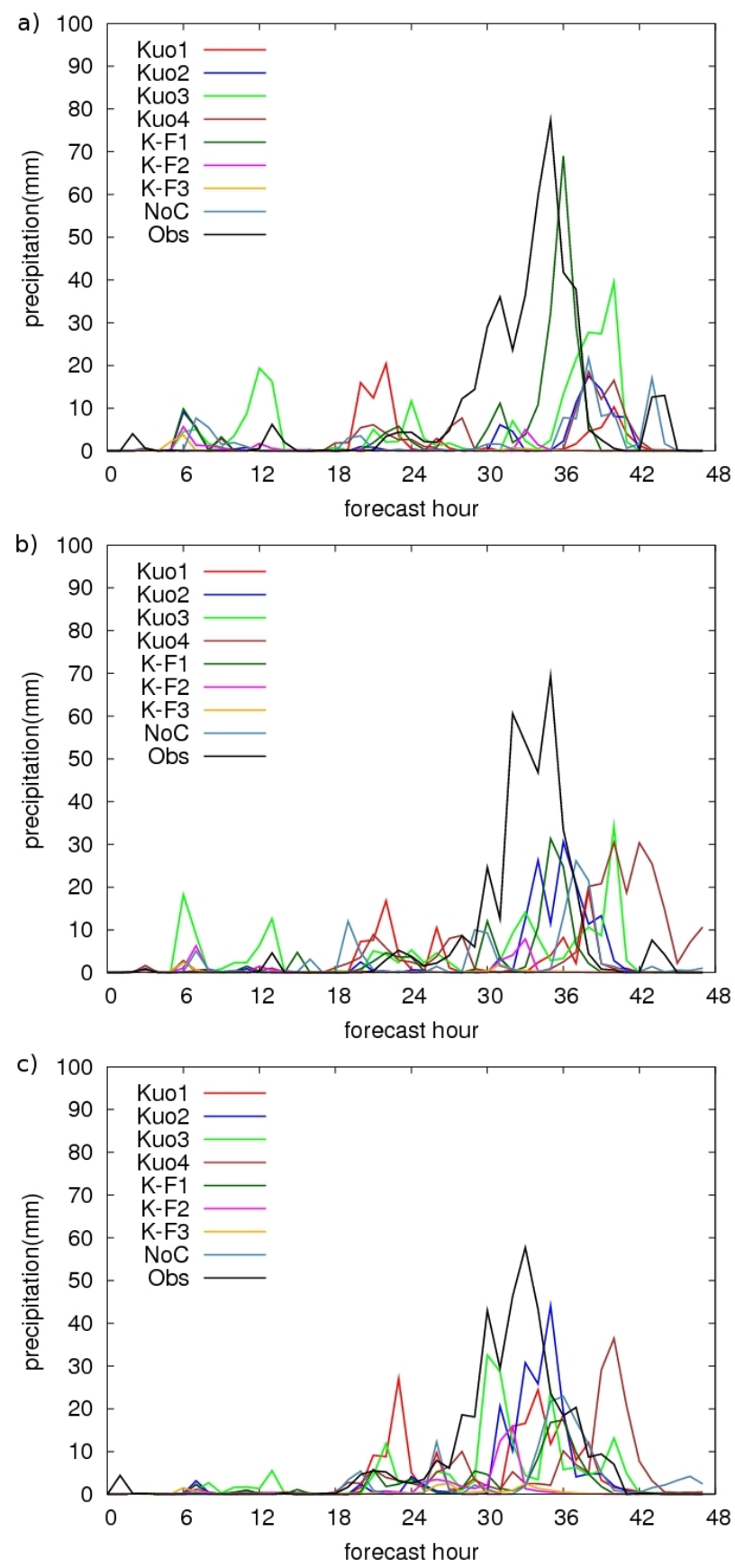

Fig. 9. Hourly evolution of RAMS forecasted and observed precipitation: (a) Alcalalí station, (b) Isbert station, (c) Tollos station $(\mathrm{mm})$

\subsection{Resolved versus parameterized precipitation}

This section deals with the effects of the activation of the $\mathrm{CP}$ in both resolved and parameterized precipitation for all grids. In a general way, Kuo and Kain-Fritsch convective parametrization schemes seem to work in opposite direction as overall accuracy in accumulated precipitation, for highest resolution grids, improves when the Kuo scheme is activated in higher resolution grids, while in the case of Kain-Fritsch scheme, model results improve when the parameterization is active only in the coarser grid and convection is explicitly resolved for inner grids.

The activation of Kain-Fritsch scheme in progressively higher resolution grids tends to diminish resolved precipitation in all grids and parameterized precipitation in outer/coarser grids. In the experiments run with the Kuo scheme activated, parameterized precipitation tends to decrease as the parameterization is activated in higher resolution grids while resolved precipitation maintains accumulated precipitation values with no great variation but reduces spatial extent over land. In the Kuo experiments, precipitation over sea significantly drops when convective parametrization schemes are activated in higher resolution grids.

As can be seen in Fig. 10, the resolved precipitation in Kain-Fritsch experiments drastically decreases in model grid 3 when the parameterization is active in the inner grids. Regarding parameterized precipitation (see supplementary material), a decreasing pattern can be found in outer grids as the parameterization scheme is activated in the inner grids. Grid 1 for KF1 experiment shows more than twice the accumulated parameterized precipitation found in the KF3 experiment. The same behavior can be found for parameterized precipitation for Kuo scheme experiments (see Supplement). In the case of resolved precipitation in Kuo experiments (Fig. 11), the activation of the convective parametrization schemes on the inner grids causes a reduction in its areal extent, especially due to the drastic decline of precipitation over the sea. Accumulated values do not show substantial variation between the Kuo experiments, mainly in the maximum precipitation area (corresponding to model Grid 4).

\subsection{Vertical cross-sections}

Figure 12 shows the equivalent potential temperature, vertical velocity and wind vectors in a vertical cross-section at $38.8^{\circ} \mathrm{N}$ across RAMS model Grid 4 on 12 October at 06:00 UTC for the eight simulations. In these vertical sections a low-level moist advection towards the coast is found for all simulations lasting for most or all the simulation time. This continuous moisture feeding, lifted up via vertical transport mainly due to orographic triggering (Pastor et al., 2010), along with the presence of instability at the middle and upper levels (Figs. 3 and 4) constituted a propitious environment for the onset and persistence of heavy rains.

In the previous hours to the onset of rainfall, vertical motion starts to appear in a more or less clear way above the coast depending on the simulation. As an example, at 00:00 UTC on 12 October (not shown) significant vertical velocity is only found in Kuol experiment, being weaker in KF1 and almost negligible in the rest of experiments. In the 

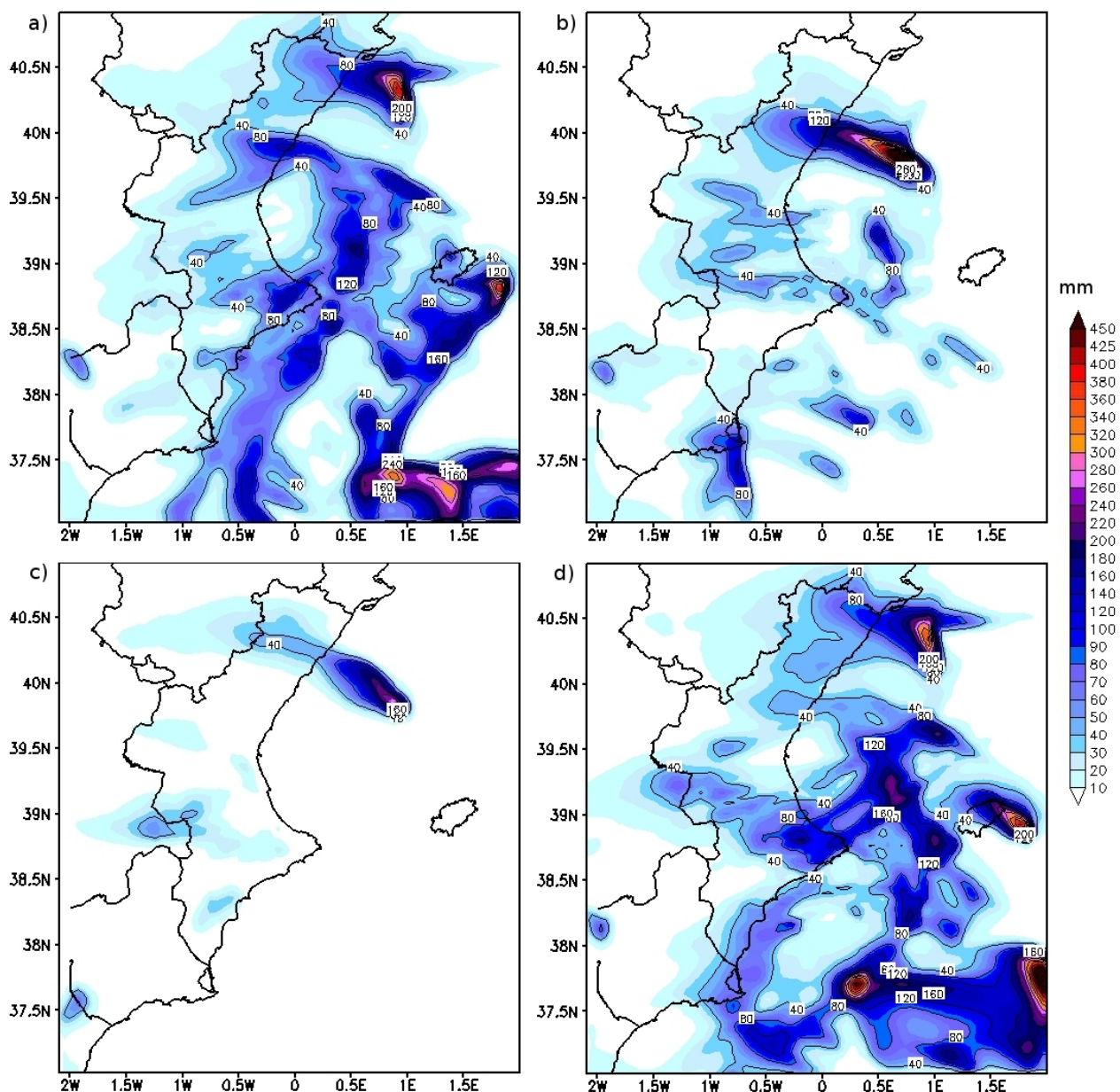

Fig. 10. RAMS grid 3 48-h accumulated resolved precipitation for KF and NoC experiments: (a) KF1, (b) KF2, (c) KF3 and (d) NoC.

maximum precipitation interval, in the hours before dawn on 12 October, strong vertical motion is found in Kuo1, Kuo2, Kuo3, KF1 and NoC experiments over the orographic barriers close to the coast (Fig. 12). The KF2 experiment shows weaker vertical velocities while the KF3 and Kuo4 do not show significant vertical movement. This situation remains in the next vertical cross-section 6 hours later but with a weakening of vertical transport in KF2 and a light increase in Kuo4. At 18:00 UTC on 12 October (not shown) vertical motion persists on Kuo1, Kuo2 and NoC and appears in Kuo4 but weakens in Kuo3. These differences in the start and the maximum timing of the vertical motion in the different simulations could be the responsible for the delay in the maximum precipitation intensities found in the model precipitation forecast (Figure 9).

\subsection{Statistical verification}

The discussion of the statistical scores is based on the 12$\mathrm{h}$ accumulation time, since values for shorter accumulation times provide essentially the same information on the skill of the different configurations of the RAMS model runs. To compute the different $12-\mathrm{h}$ accumulation precipitation periods of the whole event, hourly precipitation records described in Sect. 2 have been used. Again, observations of all meteorological stations with this information available are compared with model Grid 4 results at the closest points to each station. To compute the statistical scores, all stations available in this format have been merged. Figure 13 includes the evolution of different classical scores computed from the sum of contingency tables of the event.

Figure 13a shows the AB score for the 8 RAMS configurations as a function of the selected precipitation thresholds. For all the RAMS model configurations AB presents a similar trend towards underestimating the total precipitation area. For all the simulations the $\mathrm{AB}$ score clearly depends on the thresholds, although Kuo3 shows higher $\mathrm{AB}$ values for high precipitation intensities. Other differences can be found between the different model configurations. KF2 and KF3 are not able to reproduce the strong maxima observed; thus, their $\mathrm{AB}$ scores are lower than the others for all selected thresholds. Kuo1 and Kuo2 show a similar accuracy-decreasing 

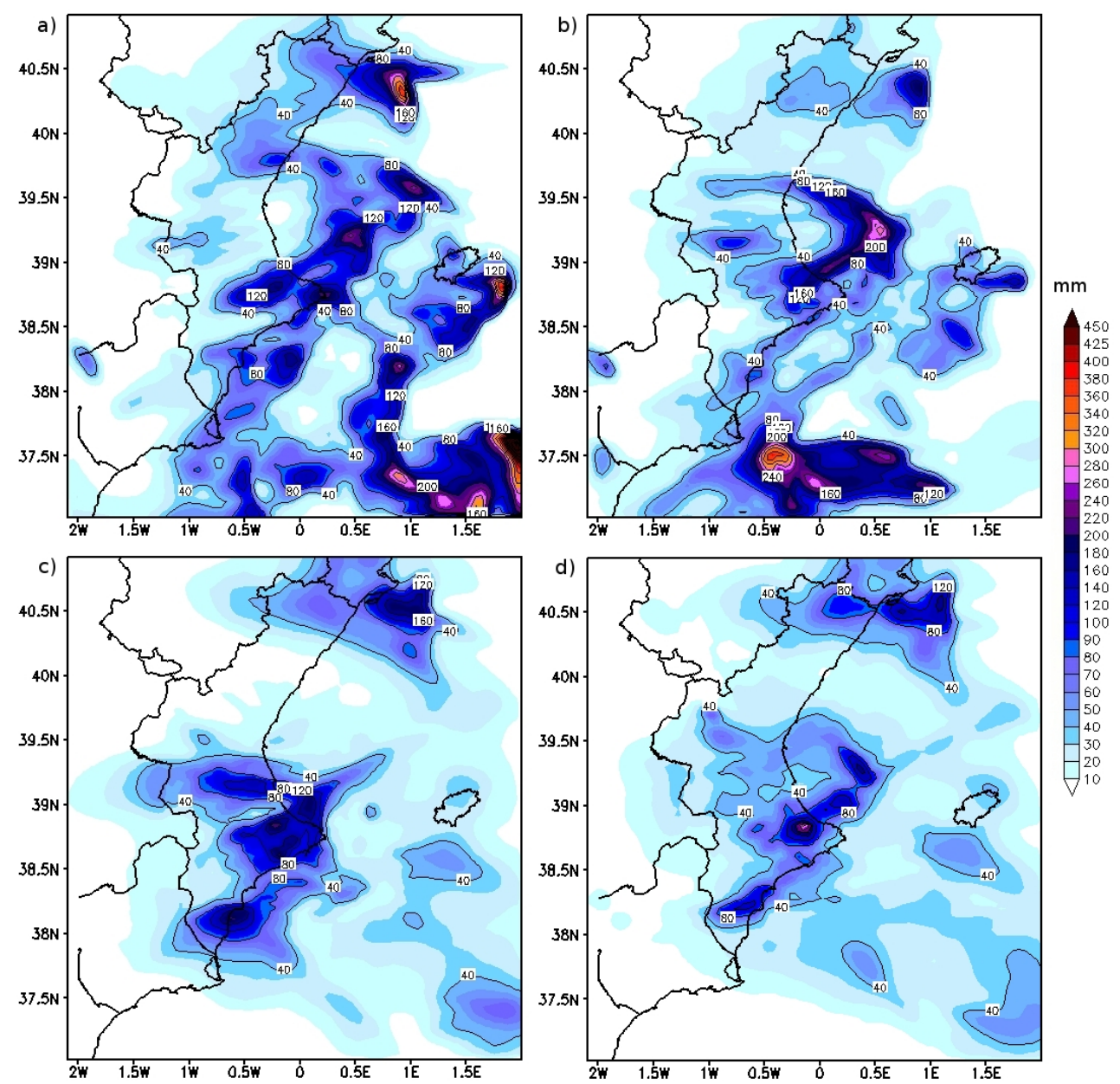

Fig. 11. RAMS grid 3 48-h accumulated resolved precipitation for Kuo experiments : (a) Kuo1, (b) Kuo2, (c) Kuo3 and (d) Kuo4.

behaviour for medium-high intensities, whereas for lower intensities Kuo2 is closer to KF1. Kuo1, Kuo2 and KF1 show a generally similar trend for $\mathrm{AB}$, with Kuo1 presenting slightly better scores in low-range intensities and very similar results in the extent of precipitation for medium-high thresholds. For all the RAMS simulations, Kuo3 seems to provide the best $\mathrm{AB}$ results for all thresholds. For low and middle precipitation intensities Kuo3 and Kuo4 are close to 1.0 (perfect score) while for higher intensities Kuo3 decreases to values near 0.6 and Kuo4 drastically drops down to $\mathrm{AB}$ values similar to those from Kuo1, Kuo2 and KF1. A notable difference between Kuo3 and the other RAMS simulations is seen for the higher precipitation intensities. Kuo3 gave a better prediction of the sharp maxima observed, as the other simulations predicted more diffuse precipitation within the verification area. The NoC experiment showed a similar behavior to that of Kuo1, Kuo2 and KF1.

The CSI (Fig. 13b) has also been examined. The CSI score measures the fraction of observed and/or forecasting events that were correctly predicted and can be thought of as the ac- curacy when correct negatives have been removed from consideration. It is sensitive to hits and penalizes both misses and false alarms; 1 is a perfect score, while 0 is the lowest possible value (Mazarakis et al., 2009). For light rain thresholds, the four Kuo, KF1 and NoC simulations show fairly good skills, with scores above 0.5 ; Kuo4 produces somewhat higher results. KF2 and KF3 show values below 0.6 , which rapidly decrease with an increasing threshold. The skill of the other simulations also decays with increasing threshold values. For medium precipitation intensities, Kuo2, Kuo3, KF1 and NoC show slightly better skills than Kuo1 and Kuo4, while the CSI score for Kuo4 and KF1 are below the other three Kuo scheme and NoC experiments for higher threshold values. There is also a notable difference between KF1, NoC and the four Kuo experiments, on the one hand, and the other two Kain-Fritsch experiments (KF2 and $\mathrm{KF} 3$ ) on the other. In this sense, the CSI for KF2 and KF3 for all thresholds are quite below the other tested schemes. Moreover, for higher precipitation intensities, KF2 has CSI values near 0 , while the CSI score for the KF3 experiment 

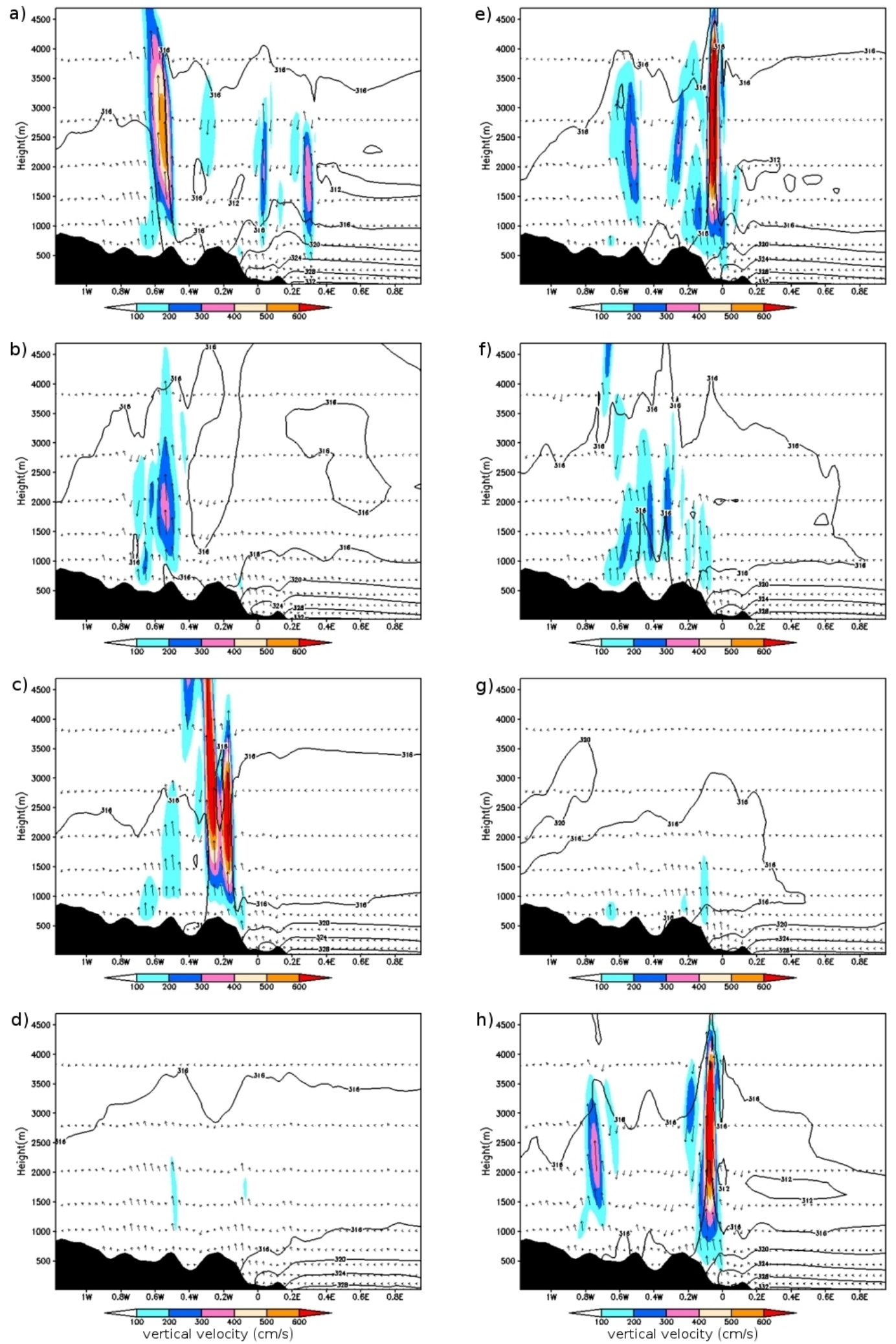

Fig. 12. Vertical cross section at $38.8^{\circ} \mathrm{N}$ RAMS equivalent potential temperature $(\mathrm{K}$, contoured), vertical velocity $(\mathrm{cm} / \mathrm{s}$, shaded color) and wind vector (arrows) on 06:00 UTC 12 October for (a) Kuo1, (b) Kuo2, (c) Kuo3, (d) Kuo4, (e) KF1, (f) KF2, (g) KF3 and (h) NoC. 

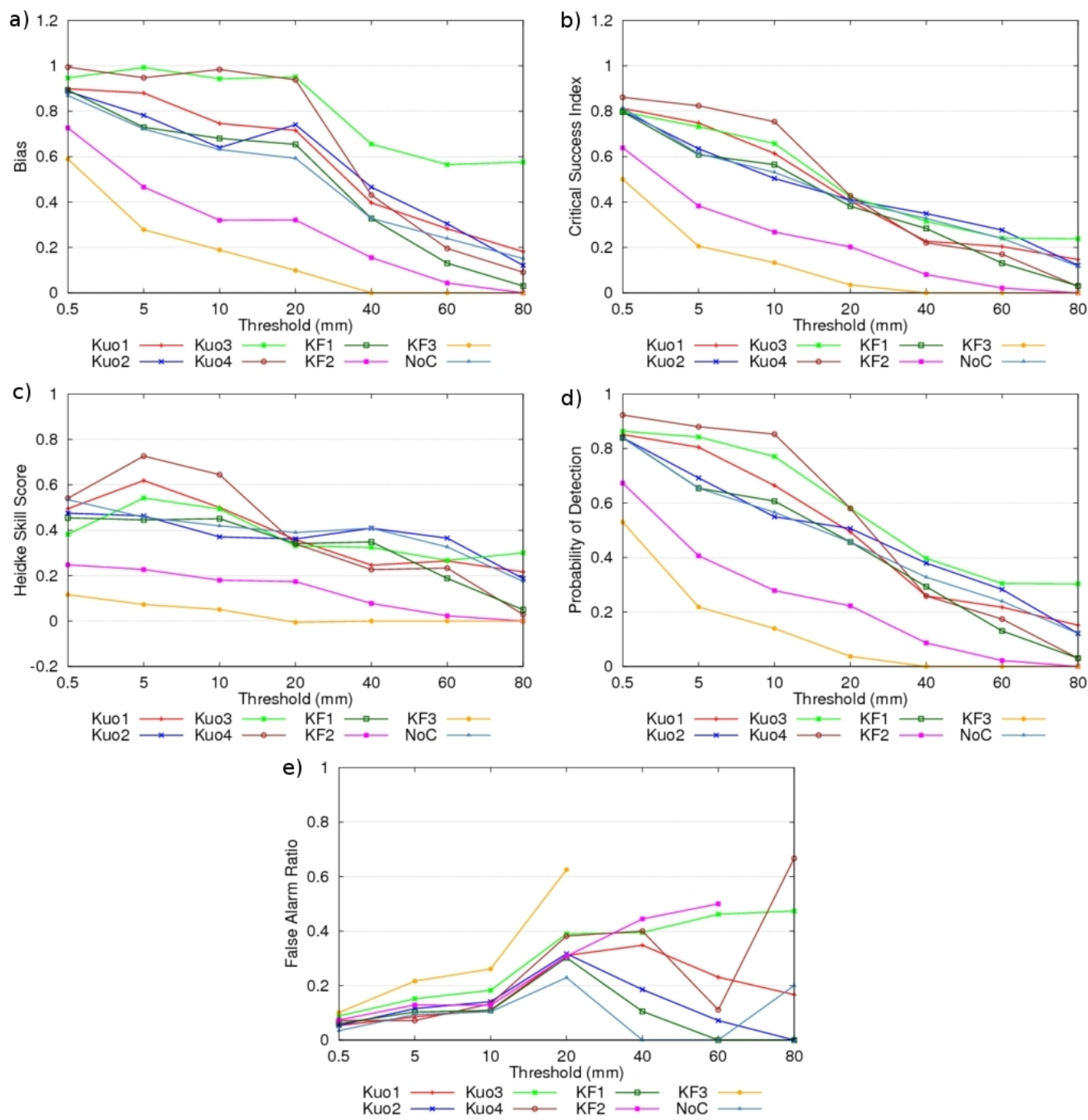

Fig. 13. RAMS skill scores: (a) Areal Bias, (b) Critical Success Index, (c) Heidke Skill Score, (d) Probability of Detection and (e) False Alarm Rate

produces 0 values from $40 \mathrm{~mm}$ on, indicating that these configurations should not be used for higher precipitation intensities, at least for this case study, as they do not reproduce the sharp maxima observed. From these results, it seems that Kuo3 outperforms the other experiments tested in this study for the highest thresholds present in heavy rain events.

Figure $13 \mathrm{c}$ shows the HSS score which is the most commonly used skill score for summarizing $2 \times 2$ contingency tables (Mazarakis et al., 2009). HSS is based on the hit rate as the basic accuracy measure, and represents the fraction of correct forecasts after eliminating those forecasts which would have been correct due to random chance (considered the reference forecast). Thus, perfect forecasts receive an HSS score of one, forecasts equivalent to the reference forecast receive a score of zero, and forecasts worse than the reference forecast receive negative scores. In comparison with the aforementioned skill scores, HSS shows a similar pattern. Thus, KF2 and KF3 produce low HSS values for all thresholds, with values near 0 for higher thresholds. It can be noted that for the case of KF3, the HSS value for the $20 \mathrm{~mm}$ threshold is near 0 but negative, indicating that this forecast is worse than the reference one. In Figure 13c, it is also shown that the differences between the KF1 configuration and the four Kuo ones are low for medium intensities, around $20 \mathrm{~mm}$, whereas they are greater for values above and below this threshold. For low and medium thresholds, Kuo 4 produces the best HSS scores while Kuol and Kuo3 produce better HSS scores than Kuo2, KF1 and NoC. On the contrary, Kuo2 and NoC produce better results for high thresholds.

To analyse the ability of the model to correctly forecast the observed precipitation, POD has been calculated and included in Fig. 13d. POD results are very similar to AB ones, 
showing a descending trend from the lower thresholds to the higher ones. Kuo4 yields the best results for thresholds below $20 \mathrm{~mm}$ while Kuo1 has better skill than Kuo2, KF1 and NoC. For thresholds above that value, Kuo3 and NoC show a better performance with Kuo3 achieving the better skills on the highest thresholds. As for the case of the AB score, Kuo3 generally produces the best POD values for all thresholds. Finally, the POD for KF2 and KF3 shows poor results, which are even worse for higher precipitation intensities. If we examine the FAR score (Fig. 13e), it shows a generally slight ascending trend for the lowest thresholds, which becomes more pronounced between 10 and $20 \mathrm{~mm}$, indicating an increase in false alarms. Within this threshold range, all simulations but KF3 show similar FAR scores, starting to deviate from each other up to $20 \mathrm{~mm}$ but still with an increasing trend especially for KF3, which produces a quick rise in false alarms. From $20 \mathrm{~mm}$ on, the behaviour of the different configurations can be divided into two groups. On the one hand, Kuo1, Kuo3, Kuo4 and KF2 follow a light ascending trend up to $40 \mathrm{~mm}$ threshold while the rest of simulations start a noticeable decreasing trend. The trend followed by Kuo3 is to increase the number of false alarms for higher thresholds while Kuo1 and Kuo4 start the declining trend above $40 \mathrm{~mm}$. On the other hand, Kuo1, Kuo2 and KF1 show an unexpected descending trend for the higher thresholds, especially in the case of Kuo2 and KF1, thus reducing the false alarm ratio for high precipitation intensity. It has to be noted that Kuo4 and NoC again increase the number of false alarms for the highest threshold. It seems that although Kuo3 and Kuo4 are better at reproducing the total amount of precipitation, Kuo2 and KF1 are better at capturing the time of the precipitation for all thresholds. This point is shown clearer in the time evolution graphs in Fig. 9. It should also be noted that, on 11 October, Kuo3 produced a high precipitation area which was not actually recorded (not shown), and increased its FAR score for the high thresholds. Due to the larger underestimation of the simulated rain fields obtained with KF2 and KF3 and the choice of the thresholds, it was not always possible to compute the FAR scores, as shown in Fig. 13e.

As can be seen in the above skill scores analysis, in general, the Kuo3 configuration seems to perform better than the other configurations tested for the amount and areal extent of precipitation while Kuo4 also obtains good performance for maximum precipitation values. On the other hand, Kuo2 and KF1 seem to better reproduce the time evolution of the precipitation, although these experiments do not produce as much precipitation as that shown with Kuo3.

\section{Conclusions}

In this work, the authors have investigated the sensitivity of RAMS model forecasts to the choice and activation of different convective parametrization schemes at different spatial scales in a torrential rain event in the Valencia region. The convective parameterization schemes implemented in RAMS are Kuo and Kain-Fritsch. The experiment consisted in using the RAMS model to run different high resolution simulations with four grids, and activating, or not, the parameterization schemes in different grids for each simulation (Table 2).

First, we analyzed the accumulated precipitation forecast from RAMS. In this rain event, two of the experiments with the Kain-Fritsch scheme activated produce unrealistically low precipitation values. The only case where the KainFritsch scheme showed an acceptable performance is the KF1 experiment in which the Kain-Fritsch parameterization is active only in the coarser grid of the simulation, while the other grids explicitly solve the microphysical package equations. Thus, activating the convection scheme at a progressively higher spatial resolution worsens the RAMS results for the Kain-Fritsch scheme. Otherwise, the Kuo convective scheme produces good results on accumulated precipitation spatial distribution for the three experiments, although it always underestimates precipitation amounts, especially in the maximum rainfall area. In this latter case, activation of the Kuo parameterization scheme in increasing spatial resolution grids for the three outer girds progressively improves the RAMS precipitation forecast regarding maximum precipitation values and spatial distribution, although underpredicting actual values, while the activation on the fourth grid, the inner highest resolution grid, improves the maximum precipitation peak but worsens the areal extent of precipitation. The experiment run without any convective parameterization scheme activated in any grid yielded good results regarding rainfall spatial distribution but underestimated precipitation values.

With respect to the time evolution of the precipitation forecast, we have studied the hourly accumulated precipitation values. As in the case of the spatial distribution of precipitation, the Kuo performs better than the Kain-Fritsch one, except in the KF1 experiment. The Kuo scheme, in general, properly reproduces the onset and the end of the precipitation event, however, the Kuol experiment (convective scheme activated only in the coarser grid) produced higher values than those recorded just before the real initiation of the event and lower values than in the other Kuo experiments during rainfall. It is notable that in the case of the KF1 experiment, the model almost fits the moment of maximum precipitation at the Alcalalí station.

In all the experiments a low-level, moist advection is found moving over the Mediterranean Sea towards the coast, feeding humidity that was lifted up by both convection and orographic triggering. Examination of the vertical velocity fields revealed differences between all the simulations. The stronger and more organized vertical updrafts in the Kuo1, Kuo2, Kuo3, KF1 and NoC experiments enhanced the moisture transport from the lower to the middle and upper levels. This resulted in stronger and more continuous moisture feeding up to the condensation levels, favouring the development of the precipitating system. For the rest of the simulations, 
both the vertical movement and the accumulated precipitation were clearly weaker. The activation of convective parameterization schemes in the inner grid seemed to diminish the available instability for both parameterized and resolved precipitation in the outer grids for this rain event, thus generating a decrease in accumulated precipitation in the outer grids.

Our second step has been a statistical analysis of the RAMS results for this particular rain event in order to present an objective validation against the comparison of forecasted/observed surface fields. Several different skill scores have been calculated for all the simulations in order to objectively verify model results against observed data. From the analysis of these skill scores, the Kuo convective scheme appears to produce better results in the precipitation forecasting than the Kain-Fritsch scheme. Only the simulation in which the Kain-Fritsch scheme was activated solely in the coarser grid showed a skill comparable to the Kuo experiments.

Therefore, based on the behaviour of the different RAMS configurations used in this study, we can say that the Kuo scheme performed better than the Kain-Fritsch one for this heavy rain event. Activating the Kuo scheme on grids with increasingly higher spatial resolution, up to $4.5 \mathrm{~km}$ in our case, improved the RAMS precipitation forecast both in accumulated values and spatial distribution. The improvement was not so significant with respect to the temporal evolution of precipitation intensities. When the Kuo scheme was activated in the highest resolution $(1.5 \mathrm{~km})$ grid model, we obtained slightly worse results in terms of the spatial distribution of precipitation but still acceptable results in terms of precipitation amounts. For this heavy rain event, the use of convective parameterization schemes in very high resolution model grids does not seem advisable. This point should be studied for any particular case, as other authors have found improvement in modelling results when using convective parameterization schemes in high resolution simulations.

In order to achieve more robust results on the effects of the different CPs available in RAMS model, it is necessary to perform this study for a statistically significant number of cases of heavy rain events. With that background, the conclusions explained before regarding the physical processes involved in torrential rain events would be more consistent and become more general for this type of events.

After this sensitivity and verification experiment, a more in-depth analysis of the physical processes involved in a rain event should be carried out to investigate the factors in the individual simulations that account for the mechanisms producing the effects on the precipitation forecast found in this work. This will be the authors' aim in future studies.
Supplementary material related to this article is available online at:

\section{http://www.nat-hazards-earth-syst-sci.net/11/343/2011/ nhess-11-343-2011-supplement.zip.}

Acknowledgements. This work has been funded by the Spanish Ministerio de Educación y Ciencia through the projects CGL2008-04550/CLI (Proyecto NIEVA), CSD2007-00067 CONSOLIDER-INGENIO 2010 (Proyecto GRACCIE) and CGL2007-65774/CLI (Proyecto MAPSAT) and the EU-funded Integrated Project CIRCE (Project. No. 036961). FNL data used for RAMS initialization are from the Research Data Archive (RDA) which is maintained by the Computational and Information Systems Laboratory (CISL) at the National Center for Atmospheric Research (NCAR). NCAR is sponsored by the National Science Foundation (NSF). The original data are available from the RDA (http://dss.ucar.edu) in dataset number ds083.2. We also want to thank the reviewers, whose comments and suggestions have greatly improved the paper, and Jackie Scheiding for the review of the English text. The CEAM Foundation is supported by the Generalitat Valenciana and BANCAIXA.

Edited by: M.-C. Llasat

Reviewed by: three anonymous referees

\section{References}

Alpert, P., Ben-Gai, T., Baharad, A., Benjamini, Y., Yekutieli, D., Colacino, M., Diodato, L., Ramis, C., Homar, V., Romero, R., Michaelides, S., and Manes, A.: The paradoxical increase of Mediterranean extreme daily rainfall in spite of decrease in total values, Geophys. Res. Lett., 29, 31-1, doi:10.1029/2001GL013554, 2002.

Bresson, R., Ricard, D., and Ducrocq, V.: Idealized mesoscale numerical study of Mediterranean heavy precipitating convective systems, Meteorol. Atmos. Phys., 103, 45-55, doi:10.1007/s00703-008-0338-z, 2009.

Castro, C., Cheng, W., Beltrán, A., Marshall Jr, C., Pielke Sr, R., and Cotton, W.: The incorporation of the Kain-Fritsch cumulus parameterization scheme in RAMS with a terrain-adjusted trigger function, in: Fifth RAMS Users Workshop, Santorini Island, Greece, 29 September-October 3, 2002.

Chen, C. and Cotton, W.: A One-Dimensional Simulation of the Stratocumulus-Capped Mixed Layer, Bound. Lay. Meteorol., 25 289-321, 1983.

Cotton, W. R., Pielke, R. A. S., Walko, R. L., Liston, G. E., Tremback, C. J., Jiang, H., McAnelly, R. L., Harrington, J. Y., Nicholls, M. E., Carrio, G. G., and McFadden, J. P.: RAMS 2001: Current status and future directions, Meteorol. Atmos. Phys., 82, 5-29, 2003.

Davolio, S., Miglietta, M. M., Moscatello, A., Pacifico, F., Buzzi, A., and Rotunno, R.: Numerical forecast and analysis of a tropical-like cyclone in the Ionian Sea, Nat. Hazards Earth Syst. Sci., 9, 551-562, doi:10.5194/nhess-9-551-2009, 2009.

Doswell III, C. A., Ramis, C., Romero, R., and Alonso, S.: A diagnostic study of three heavy precipitation episodes in the western Mediterranean, Wea. Forecasting, 13, 102-124, 1998.

Estrela, M., Pastor, F., and Millán, M.: Air Mass Change along Trajectories in the Western Mediterranean Basin in the Torrential 
Rain Events in the Valencia Region, in: Mediterranean Storms, Proceedings of the 4th EGS Plinius Conference 2002, 2003.

Federico, S., Avolio, E., Bellecci, C., Lavagnini, A., Colacino, M., and Walko, R. L.: Numerical analysis of an intense rainstorm occurred in southern Italy, Nat. Hazards Earth Syst. Sci., 8, 1935, doi:10.5194/nhess-8-19-2008, 2008.

Gómez, I., Pastor, F., and Estrela, M.: Sensitivity of precipitation forecasts to convective parameterization in the October 2007 Flash Flood in the Valencia Region (Eastern Spain), Adv. Geosci., 26, 7-11, doi:10.5194/adgeo-26-7-2010, 2010.

Hamill, T. M.: Hypothesis tests for evaluating numerical precipitation forecasts, Wea. Forecasting, 14, 155-167, 1999.

Homar, V., Romero, R., Stensrud, D. J., Ramis, C., and Alonso, S.: A Quasi-tropical Cyclone Over The Western Mediterranean: Dynamical Vs Boundary Factors, Quart. J. R. Meteorol. Soc., 129, 1469-1490, 2002.

Jansa, A., Genoves, A., Picornell, M., Campins, J., Riosalido, R., and Carretero, O.: Western Mediterranean cyclones and heavy rain. Part 2: Statistical approach, Meteorol. Appl., 8, 43-56, 2001.

Kain, J. and Fritsch, J.: Convective parameterization for mesoscale models: The Kain-Fritsch scheme. The representation of cumulus convection in numerical models, pp. 165-170, 24, Meteorological Monographs, American Meteorological Society, 1993.

Kotroni, V. and Lagouvardos, K.: Precipitation forecast skill of different convective parameterization and microphysical schemes: application for the cold season over Greece, Geophys. Res. Lett., 28, 1977-1980, 2001.

Kotroni, V. and Lagouvardos, K.: Evaluation of MM5 HighResolution Real-Time Forecasts over the Urban Area of Athens, Greece, J. Appl. Meteorol., 43, 1666-1678, 2004.

Lagouvardos, K., Kotroni, V., Dobricic, S., Nickovic, S., and Kallos, G.: The storm of October 21-22, 1994, over Greece: Observations and model results, J. Geophys. Res.-Atmos., 101, $26217-$ 26226, 1996.

Lagouvardos, K., Kotroni, V., Nickovic, S., Jovic, D., Kallos, G., and Tremback, C.: Observations and model simulations of a winter sub-synoptic vortex over the central Mediterranean, Meteorol. Appl., 6, 371-383, 1999.

Lebeaupin, C., Ducrocq, V., and Giordani, H.: Sensitivity of torrential rain events to the sea surface temperature based on highresolution numerical forecasts, 111, D12110, 12110-12110, J. Geophys. Res.-Atmos., 2006.

Maheras, P., Flocas, H., Patrikas, I., and Anagnostopoulou, C.: A 40 year objective climatology of surface cyclones in the Mediterranean region: spatial and temporal distribution, Int. J. Climatol., 21, 109-130, 2001.

Mariani, S., Casaioli, M., Accadia, C., Llasat, M. C., Pasi, F., Davolio, S., Elementi, M., Ficca, G., and Romero, R.: A limited area model intercomparison on the "Montserrat-2000" flashflood event using statistical and deterministic methods, Nat. Hazards Earth Syst. Sci., 5, 565-581, doi:10.5194/nhess-5-5652005, 2005.

Mazarakis, N., Kotroni, V., Lagouvardos, K., and Argiriou, A. A.: The sensitivity of numerical forecasts to convective parameterization during the warm period and the use of lightning data as an indicator for convective occurrence, Atmos. Res., 94, 704-714, 2009.
Meneguzzo, F., Pasqui, M., Menduni, G., Messeri, G., Gozzini, B., Grifoni, D., Rossi, M., and Maracchi, G.: Sensitivity of meteorological high-resolution numerical simulations of the biggest floods occurred over the Arno river basin, Italy, in the 20th century, J. Hydrol., 288, 37-56, 2004.

Miglietta, M. M. and Regano, A.: An observational and numerical study of a flash-flood event over south-eastern Italy, Nat. Hazards Earth Syst. Sci., 8, 1417-1430, doi:10.5194/nhess-8-1417-2008, 2008.

Millán, M., Estrela, M., and Miró., J.: Rainfall Components: Variability and Spatial Distribution in a Mediterranean Area (Valencia Region), J. Climate, 18, 2682-2705, 2005.

Molinari, J.: A General Form of Kuo's Cumulus Parameterization, Mon. Weather Rev., 113, 1411-1416, 1985.

Pastor, F., Estrela, M. J., Peñarrocha, D., and Millán, M. M.: Torrential rains on the Spanish Mediterranean coast: Modeling the effects of the sea surface temperature, J. Appl. Meteorol., 40, 1180-1195, 2001.

Pastor, F., Gómez, I., and Estrela, M. J.: Numerical study of the October 2007 flash flood in the Valencia region (Eastern Spain): the role of orography, Nat. Hazards Earth Syst. Sci., 10, 13311345, doi:10.5194/nhess-10-1331-2010, 2010.

Peñarrocha, D., Estrela, M. J., and Millán, M.: Classification of daily rainfall patterns in a Mediterranean area with extreme intensity levels: The Valencia region, Int. J. Climatol., 22, 677695, 2002.

Pérez-Landa, G., Ciais, P., Sanz, M. J., Gioli, B., Miglietta, F., Palau, J. L., Gangoiti, G., and Millán, M.: Mesoscale circulations over complex terrain in the Valencia coastal region, Spain Part 1: Simulation of diurnal circulation regimes, Atmos. Chem. Phys., 7, 1835-1849, doi:10.5194/acp-7-1835-2007, 2007.

Pielke, R., Cotton, R., Walko, R., Tremback, C., Lyons, W., Grasso, L., Nicholls, M., Moran, M., Wesley, D., Lee, T., and Copeland, J.: A Comprehensive Meteorological Modelling System - RAMS, Meteorol. Atmos. Phys., 49, 69-91, 1992.

Romero, R., Doswell III, C. A., and Ramis, C.: Mesoscale Numerical Study of two Cases of Long-Lived Quasistationary Convective Systems Over Eastern spain, Mon. Weather Rev., 128, 3731-3751, 2000.

Salvador, R., Calbó, J., and Millán, M.: Horizontal Grid Size Selection and its Influence on Mesoscale Model Simulations., J. Appl. Meteorol., 39, 1311-1329, 1999.

Solomon, S., Qin, D., Manning, M., Chen, Z., Marquis, M., Averyt, K. B., Tignor, M., and Miller, H. L.: Intergovernmental Panel on Climate Change (IPCC): Climate Change 2007: The Physical Science Basis, Cambridge University Press, Cambridge, UK and New York, NY, USA, 2007.

Trigo, I., Bigg, G. R., and Davies, T. D.: Climatology of Cyclogenesis Mechanisms in the Mediterranean, Mon. Weather Rev., 130, 549-569, 2002.

Walko, R. L., Cotton, W. R., Meyers, M. P., and Harrington, J. Y.: New RAMS cloud microphysics parameterization. Part I: The single-moment scheme, Atmos. Res., 38, 29-62, 1995.

Warner, T. T. and Hsu, H.-M.: Nested-Model Simulation of Moist Convection: The Impact of Coarse-Grid Parameterized Convection on Fine-Grid Resolved Convection, Mon. Weather Rev., 128, 2211-2231, 2000. 